\title{
CONCEPÇÕES DE PROFESSORES FORMADORES ACERCA DO CARÁTER SOCIOTÉCNICO DOS PROBLEMAS DE ENGENHARIA
}

\section{CONCEPTIONS OF TRAINING TEACHERS ABOUT THE SOCIO TECHNICAL CHARACTER OF PROBLEMS IN ENGINEERING}

\author{
Leandro Bordin ${ }^{1}$, Walter Antonio Bazzo ${ }^{2}$ \\ Recebido: julho/2019 Aprovado: setembro/2021
}

\begin{abstract}
Resumo: 0 trabalho apresenta e discute concepções de professores formadores acerca da simbiótica relação entre desenvolvimento tecnológico e desenvolvimento social desenvolvimento sociotécnico - na formação e atuação dos profissionais de Engenharia. Considerando uma abordagem qualitativa, os dados e informações foram construídos por meio de entrevistas semiestruturadas com 29 (vinte e nove) professores de 5 (cinco) cursos de Engenharia da Universidade Federal da Fronteira Sul (UFFS) e as análises e categorizações foram realizadas usando a metodologia de Análise de Conteúdo. Tendo como categoria primeira 'o caráter sociotécnico dos problemas de Engenharia', os resultados e discussões estão circunscritos em torno das seguintes subcategorias: (a) o modelo linear de desenvolvimento: a tecnologia neutra e determinista no contexto capitalista e (b) as (in)certezas: o desenvolvimento tecnológico em debate. A prevalência de concepções tradicionais acerca do desenvolvimento tecnológico, em um lócus de pesquisa empírica que apresenta profícuas possibilidades de desenvolvimento de Tecnologias Sociais, reforça a falta de entendimento e comprometimento acerca do papel social da Engenharia e revela a dificuldade de superação de modelos formativos historicamente consolidados.
\end{abstract}

Palavras-chave: Ciência, Tecnologia e Sociedade (CTS), Desenvolvimento sociotécnico, Educação em Engenharia.

\begin{abstract}
This work presents and discusses conceptions of training teachers about the symbiotic relation between technological development and social development - socio technical development - in the formation and acting of the professionals in Engineering. Taking into consideration a qualitative approach, the data were constructed through semi-structured interviews with 29 professors from 5 Engineering courses at Universidade Federal da Fronteira Sul (UFFS) and the analyses and categorizations were conducted via use of the Analysis of Content methodology. Having as primary category 'the socio technical character of the problems in Engineering', the results and discussions are circumscribed around the following categories: (a) the linear model of development: the neutral and deterministic technology in the capitalist context and (b) the (un)certainties: the technological development at debate. The prevalence of traditional conceptions about the technological development in a locus of empirical research that presents meaningful possibilities for the development of Social Technologies, reinforces the lack of understanding and commitment around the social role of Engineering and reveals the difficulty of overcoming formative models historically consolidated.
\end{abstract}

Keywords: Science, Technology and Society (STS), Socio technical development, Education in Engineering.

1 (iD ORCID: https://orcid.org/0000-0002-4703-6671 - Doutor em Educação Científica e Tecnológica pela Universidade Federal de Santa Catarina (UFSC). Professor da Universidade Federal da Fronteira Sul (UFFS), Chapecó, Santa Catarina, Brasil. Rodovia SC 484 Km 02, Bairro Fronteira Sul, CEP: 89815-899, Chapecó, Santa Catarina, Brasil. E-mail: Ibordin@uffs.edu.br.

2 (D) ORCID: https://orcid.org/0000-0003-0093-8229 - Doutor em Educação pela Universidade Federal de Santa Catarina (UFSC). Professor da Universidade Federal de Santa Catarina (UFSC), Florianópolis, Santa Catarina, Brasil. Campus Reitor João David Ferreira Lima, s/n, Bairro Trindade, CEP: 88040-900, Florianópolis, Santa Catarina, Brasil. E-mail: walter.bazzo@ufsc.br. 


\section{Introdução}

Quando se discute a educação em Engenharia é quase que unânime o desejo principalmente em documentos - de que tenhamos uma formação crítica, reflexiva, humanista e, por consequência, comprometida com as questões sociais. Nesse sentido, as diretrizes curriculares nacionais (DCNs), documento base para a concepção de cursos de Engenharia, tanto na versão de 2002 (BRASIL, 2002), quanto na atual do ano de 2019 (BRASIL, 2019), preconizam que o perfil do egresso esteja pautado num profissional capaz de projetar soluções numa perspectiva multi e transdisciplinar com seus aspectos políticos, econômicos, sociais, ambientais e culturais e, ainda, habilitado a atuar com isenção de qualquer tipo de discriminação e comprometido com a responsabilidade social e o desenvolvimento sustentável. Em síntese o que se pretende é que a formação e a atuação extrapolem o aspecto puramente técnico - e historicamente reproduzido - da engenharia.

Apesar das muitas e expressivas produções no âmbito do campo de estudos CTS, as quais estão em estreito alinhamento com a orientação supracitada, é preciso admitir, infelizmente, pouca efetividade dessa abordagem nos processos educacionais no campo das Engenharias (BAZZO, 2014). Dessa forma, segue-se perpetuando um paradoxo na profissão: ao mesmo tempo em que almejamos - e até exigimos - que nossos estudantes e profissionais desenvolvam características de criticidade, coletividade e solidariedade, continuamos tratando de forma dicotômica as questões técnicas e sociais que constituem a profissão.

Nesse sentido, algumas indagações norteiam a construção deste trabalho ${ }^{1}$. De que forma o desenvolvimento tecnológico e suas implicações em termos de desenvolvimento social é percebido e discutido nos cursos de Engenharia? O processo formativo em Engenharia, para além da formação técnica/tecnológica, dá conta de formar cidadãos verdadeiramente comprometidos e responsáveis com os problemas - políticos, econômicos, sociais, ambientais e culturais - contemporâneos?

Ao investigar as concepções dos professores formadores acerca da sempre simbiótica relação entre desenvolvimento tecnológico e desenvolvimento social - desenvolvimento sociotécnico - o objetivo da discussão é ressaltar as potencialidades - e a urgente necessidade - de uma educação em Engenharia mais crítica, integradora e interdisciplinar.

\section{A Engenharia numa perspectiva sociotécnica}

A educação em Engenharia vem sendo problematizada, nos últimos anos, em trabalhos que, com diferentes abordagens teórico-metodológicas e com foco de investigação em distintos cenários educativos, objetivam pela via da educação desconstruir a crença de que a ciência e a

\footnotetext{
${ }^{1} \mathrm{O}$ presente artigo é parte de um trabalho mais amplo desenvolvido pelo primeiro autor, sob orientação do segundo, e apresenta o primeiro de cinco eixos de problematização, discussão e proposição em torno de uma perspectiva sociotécnica para a educação em Engenharia. A pesquisa mais ampla - documental e empírica - está circunscrita em torno das seguintes categorias: (1) o caráter sociotécnico dos problemas de Engenharia; (2) o perfil do profissional de Engenharia construído pelos professores formadores; (3) o diálogo entre a perspectiva sociotécnica de desenvolvimento e a educação em Engenharia; (4) as atividades docentes e suas articulações com o desenvolvimento regional integrado, sustentável e solidário; e (5) o professor formador e a necessidade de formação.
} 
tecnologia são neutras, autônomas, deterministas e benfeitoras em sua totalidade. Destacamos aqui os trabalhos de Bazzo (1998), Linsingen (2002), Fraga (2007), Menestrina (2008), Carletto (2009) e Jacinski (2012), os quais têm como elemento balizador o referencial proporcionado pelo campo de estudos CTS - Ciência, Tecnologia e Sociedade. As pesquisas, reflexões e proposições dos referidos autores têm pensado o processo formativo em Engenharia na estreita relação entre questões técnicas e sociais.

Muitos desafios estão presentes na efetivação dessa diferente abordagem de educação em Engenharia e mudanças conceituas e epistemológicas são prementes neste contexto. A consciência sociotécnica na formação e atuação dos profissionais de Engenharia necessita, segundo Auler (2007, p. 1), de "configurações curriculares mais sensíveis ao entorno, mais abertas a temas, a problemas contemporâneos marcados pela componente científicotecnológica". De acordo com o autor é necessário superar configurações pautadas unicamente por conteúdos disciplinares e implantar práticas articuladas a partir de temas e problemas de relevância social, cuja complexidade é mais bem contemplada por práticas interdisciplinares.

Dagnino $(2014 ; 2016)$ argumenta que o que dificulta o alinhamento entre os aspectos técnicos e sociais na formação e atuação dos profissionais de Engenharia, é a dificuldade de superação, por parte da comunidade de pesquisa - cientistas, tecnólogos e engenheiros -, do(s) modelo(s) cognitivo(s) que perpetuam a crença de que a tecnologia é neutra e determinista.

Enfrentamos, nesse cenário, um considerável desafio considerando a formação tradicional dos(as) engenheiros(as) que atuam como docentes. Bazzo $(2014$, p. 13) destaca que, nos atuais moldes da educação tecnológica, se estabelece um "círculo vicioso", uma vez que os profissionais formados em tal realidade e que atuam como professores "perpetuam não só os aspectos positivos necessários à manutenção do estilo de pensamento da comunidade profissional, mas também os seus desacertos".

Muitos profissionais de Engenharia carregam a consciência de que os seus trabalhos têm implicações sociais, no entanto não sabem e/ou não conseguem lidar satisfatória e coerentemente com essa inter-relação. "Considerar unicamente os detalhes técnicos e deixar de lado outros aspectos é a opção mais cômoda; além disso essa é a forma como foram educados" (PACEY, 1990, p. 26). Isso explica, em grande medida, porque ações curriculares de tratamento transversal com o objetivo de ampliar o entendimento e o comprometimento social da profissão não conseguem ser materializadas por muitos dos professores formadores.

\section{Aspectos metodológicos da pesquisa}

A investigação em questão teve como lócus os 5 (cinco) cursos de Engenharia ofertados pela Universidade Federal da Fronteira Sul: Engenharia Ambiental e Sanitária (nos campi de Chapecó/SC, Erechim/RS e Cerro Largo/RS); Engenharia de Aquicultura (no campus Laranjeiras do Sul/PR); e Engenharia de Alimentos (no campus Laranjeiras do Sul/PR).

A escolha metodológica da UFFS como estudo de caso se deve, principalmente, ao seu perfil institucional, o qual apresenta, num contexto contra hegemônico, profícuas possibilidades para o desenvolvimento de Tecnologias Sociais. Neste sentido, convém destacar três aspectos: 
a vinculação da UFFS com movimentos sociais desde sua idealização, criação e processo de consolidação; a marca institucional popular amplamente sublinhada nos documentos e práticas institucionais; e por fim, o compromisso com o desenvolvimento regional integrado, sustentável e solidário (UFFS, 2019).

Para investigar as concepções dos professores formadores acerca das relações sociotécnicas da formação e atuação dos profissionais de Engenharia foi definido como critério de inclusão que os professores entrevistados deveriam ministrar disciplinas no domínio específico dos cursos em questão. No âmbito da UFFS, que organiza o currículo de seus cursos em torno de três domínios - comum, conexo e específico -, o domínio específico é composto basicamente pelas componentes curriculares e atividades que envolvem exclusivamente a área de foco do curso de graduação. Entendida como a formação que permitirá ao estudante o exercício profissional, este domínio nos cursos de Engenharia é composto em sua totalidade ou quase totalidade - por professores com formação em Engenharia.

O contato com as coordenações de curso permitiu identificar 42 (quarenta e dois) professores que atenderam os critérios de inclusão da pesquisa. Após os contatos individuais terem sido realizados, 29 (vinte e nove) convites foram aceitos, o que corresponde a uma amostra de $69 \%$ (sessenta e nove por cento) do total inicialmente projetado.

A análise das entrevistas foi realizada por meio da metodologia de Análise de Conteúdo. O percurso metodológico começou pela definição de categorias primeiras de análise. Alguns autores chamam esse movimento de estabelecimento de categorias a priori ou categorias prévias. Optamos por não usar, principalmente, a expressão 'a priori' para evitar a interpretação de que elas já estavam delineadas antes mesmo do início da investigação. Ao falar em categorias primeiras destacamos que elas são resultados de um processo que se iniciou com a definição do problema de pesquisa e dos objetivos que nortearam a busca pelas respostas. Além disso, essas categorias primeiras são reflexos da construção teórica acerca do objeto de pesquisa e das intencionalidades materializadas, em forma de perguntas, no instrumento de coleta de dados e informações.

A definição da categoria primeira "O caráter sociotécnico dos problemas de Engenharia" orientou a formulação da(s) pergunta(s) que, ao ser(em) elaborada(s) e discutida(s) com cada entrevistado, pudesse apresentar elementos para a compreensão da temática. De posse do conteúdo das entrevistas, a Análise de Conteúdo nos conduz por um percurso organizado do qual emergem novas compreensões e entendimentos sobre o fenômeno estudado. Constitui-se de cinco momentos metodológicos: (1) preparação, (2) unitarização, (3) (sub)categorização, (4) descrição e (5) análise/interpretação (BARDIN, 1977; MORAES, 1999).

A etapa de preparação foi composta pela organização e codificação do material transcrito. Também, fez parte dessa etapa uma primeira leitura compreensiva, nos termos de Engers (2000), em que buscamos traçar as primeiras relações entre o conteúdo dos textos e a construção teórica acerca do tema estudado. Para facilitar a etapa subsequente - unitarização -, destacamos usando uma palheta de cores os trechos onde haviam correspondências.

O trabalho continuou pela identificação em cada entrevista dos elementos de fala relacionados com a categoria primeira analisada. O trabalho, nesse ponto, foi, então, de 
varredura do texto por meio de uma ou mais leituras a fim de encontrar todos os elementos relevantes relacionados com a categoria primeira. Nesse movimento circular e cíclico que constitui a unitarização foi possível identificar convergências e divergências por meio de unidades de análise e, então, destacar subcategorias emergentes do conjunto de entrevistas. Tais subcategorias constituem os principais elementos de problematização e discussão sobre a temática pesquisada.

\section{As concepções dos professores engenheiros}

O elemento disparador da entrevista para a categoria primeira "O caráter sociotécnico dos problemas de Engenharia" foi a assertiva do modelo tradicional de desenvolvimento que preconiza uma relação linear entre 'avanço' tecnológico, 'crescimento' econômico e desenvolvimento social. Ao apresentar tal linearidade - "O que você tem a dizer sobre a seguinte afirmativa: Investimento em desenvolvimento tecnológico implica em bem-estar e riqueza para o país e para o conjunto da população" - foi solicitado que o entrevistado tecesse comentários a respeito. Num plano flexível de conversa possibilitada pela entrevista semiestruturada novos questionamentos e esclarecimentos foram sendo construídos na medida em que o entrevistado elaborava sua compreensão sobre o tema.

Para organizar as tantas informações e relações provenientes das falas dos professores que identificaremos pela letra $P_{-}^{-}$, o quadro 1 apresenta o ir e vir do movimento de desconstrução do texto inicialmente analisado - unitarização - e, posteriormente, de construção dos novos significados - (sub)categorização - em busca de responder aos objetivos da pesquisa - análise/interpretação. Convém explicar, neste ponto, que os termos e/ou expressões mais representativos(as) das unidades de análise - destacados em negrito - foram o mote para aglutinar as convergências e fazer, assim, emergir as subcategorias.

Quadro 1: Processo de unitarização e (sub)categorização

\begin{tabular}{|l|c|}
\hline \multicolumn{2}{|c|}{ O caráter sociotécnico dos problemas de Engenharia } \\
\hline \multicolumn{1}{|c|}{ Unidades de análise } & $\begin{array}{c}\text { Subcategorias de } \\
\text { análise }\end{array}$ \\
\hline \multicolumn{1}{|c|}{ Termos/Expressões mais representativos(as) } & \\
\hline $\begin{array}{l}\text { P5: "Eu concordo 100\% [com o modelo linear de desenvolvimento]. } \\
\text { Medir crescimento é fácil. Só que métrica de desenvolvimento é um } \\
\text { pouquinho mais difícil, embora exista. E uma das métricas - eu estudo } \\
\text { macroeconomia, é meu interesse paralelo -, uma das métricas mais } \\
\text { simples de você medir desenvolvimento econômico é a relação do } \\
\text { investimento em PD, Pesquisa e Desenvolvimento, com o PIB. Mas tem } \\
\text { outras métricas de formação de capital fixo por PIB. Claro que isso é énento: a } \\
\text { tecnologia neutra e } \\
\text { aplicado mais para os países ricos. O nosso quadro atual de país de renda } \\
\text { média, quando a gente compara com o mundo, se nós não } \\
\text { desenvolvermos capacidade produtiva... fica difícil” } \\
\text { P6: “Eu acredito que sim [modelo linear de desenvolvimento]. Embora } \\
\text { recentemente eu tenha ouvido uma palestra de um alemão, que falou } \\
\text { muito no futuro tecnológico do país, e a visão dele é bastante } \\
\text { assustadora, porque a questão é tão controlada hoje em dia }\end{array}$ \\
\hline
\end{tabular}


digitalmente, ninguém mais tem privacidade, então nesses termos ele visualiza um mundo muito mecânico, muito robotizado, que é até assustador. Mas não sei, isso talvez demore um pouco".

P1: "Na verdade, quando se busca o desenvolvimento de tecnologias, indiretamente ou até diretamente, vai afetar a população. É um ganho social quando se tem um desenvolvimento tecnológico".

P7: "Eu acho que sim. Acho que é uma tendência".

P8: "Melhoria da qualidade de vida... empregos e melhores salários, coisas assim: melhorias da qualidade de vida".

P8: "Não há desenvolvimento sem Engenharia, não tem como fazer as coisas sem Engenharia. Tanto que quando deu esse boom econômico [refere-se aos últimos 10 anos] uma das classes mais valorizadas foi a dos engenheiros".

P12: "Concordo plenamente. Eu acho que são variáveis diretamente proporcionais. Com certeza não há como negar isso aí... Tem que haver investimento tecnológico para que a sociedade se desenvolva".

P13: " $100 \%$, concordo. Eu acho que quanto mais tecnologia mais qualidade de vida para todo mundo".

P17: "Porque você tem mais dinheiro girando e com mais dinheiro girando alguma coisa acaba sendo em benefício da sociedade".

P18: "Eu acredito $100 \%$ nisso. Acredito que não só a engenharia, não só o desenvolvimento tecnológico, mas também humano. Mas é consequência, não é?".

P20: "Porque se a gente conseguisse um maior desenvolvimento [tecnológico] a gente pararia de comprar de fora [importação de tecnologias] e, então, conseguiria mais emprego para as pessoas que vão estar desenvolvendo as coisas aqui dentro. $E$ aí eu acho que vai desencadeando".

P24: “Nossa! É um ponto fundamental. O que nós precisamos é parar de exportar produtos, digamos assim, primários e começar a agregar valor internamente. No momento que eu agrego valor, eu preciso mandar algo mais qualificado, a gente sabe que a qualidade do trabalho é diferente também, e com isso, teoricamente, a qualidade de vida da população em geral melhora".

P27: "Isso é fundamental. A Engenharia tem um papel fundamental nesse processo onde as tecnologias desenvolvidas vêm em benefício da população. Proporcionam melhor qualidade de vida. Então a Engenharia tem um papel fundamental nisso. Sem a Engenharia o país não desenvolve".

P28: "Eu acredito que sim. Até por ter feito intercâmbio, eu morei um ano nos Estados Unidos, tive contato com uma cultura totalmente diferente e lá eles têm um investimento muito pesado nessa parte científica, tecnológica. Você não tem noção. Extrapola todo o senso de realidade. A quantidade de dinheiro que é investido em tecnologia e aí, tu percebes que por eles terem muita empresa em tecnologia, também tem muito acesso à própria tecnologia que eles desenvolvem".

P29: "Eu concordo plenamente com essa afirmativa de que se tu investir em tecnologia, tu vai ter um conjunto de melhorias no país, sim."

O modelo linear de desenvolvimento: a tecnologia neutra e determinista no contexto capitalista 
P3: "Se o país fosse sério diria que isso é totalmente verdade. Mas se você tiver isso [desenvolvimento tecnológico] e não conseguir ter acesso, se grande parte da população não conseguir ter acesso, ou participar desse grande investimento, talvez, a gente não vai ter esse efeito positivo".

P4: "É um caminho de duas vias aí. Realmente muitas tecnologias vêm trazer conforto pra gente. Elas vêm trazer comodidade. Mas se a gente pensar que quanto maior a produção, mais descarte você vai ter, então vai chegar uma hora que essa linha tênue do limite de qualidade de vida não vai ser bem assim, vai ser ao contrário".

P11: "Eu acho que sim. Se a gente tivesse mais desenvolvimento tecnológico, mais inovação, sendo propriedade nossa, propriedade do país, a gente teria uma qualidade de vida melhor. Mas, da maneira que está hoje, a ciência e a tecnologia não conseguem ser alavancadas mais só com o dinheiro para a ciência e tecnologia. Eu vejo muitas crianças sendo malformadas e, talvez, no futuro não vai adiantar só dar dinheiro para a ciência e a tecnologia".

P21: "Eu acredito, sim, que a gente tem que ter um país desenvolvido tecnologicamente, $\mathbf{o}$ que não significa empresas privadas explorando e tendo lucros unicamente, mas no contexto geral as pessoas terem noção do que faz bem para elas. Que aquela tecnologia veio para ajudar e não unicamente para gerar dinheiro para quem está vendendo".

P25: "Eu concordo plenamente, mas esse desenvolvimento tem que ter aquelas [refere-se a outro momento da entrevista] considerações dos aspectos políticos, econômicos e sociais. Desenvolvimento tecnológico considerando os aspectos sociais".

P16: "Olha... está certo, mas para mim, o que falta é investimento em educação".

P9: "Eu acho que até que sim, mas é necessário entender o que é a tecnologia e no que isso reflete. Eu acho que esses investimentos na área de tecnologia eles não podem ficar focados apenas em uma área da sociedade. A gente tem que investir na tecnologia voltada a pesquisa científica dentro das universidades e nas entidades, não é só investir nas empresas, esse é um erro dos investimentos eu acho".

P20: "O pessoal trabalha dentro da tecnologia neutra... Eu não tinha a dimensão da Tecnologia Social. Ano passado comecei a escarafunchar e achei um debate fantástico... É uma área que politiza a tecnologia".

P10: "Eu acredito que só fomentar o desenvolvimento tecnológico, sem você fomentar outras questões... como a educação, e incluo aqui o desenvolvimento como cidadão, a gente não vai ter o êxito que a gente precisa".

P26: "Para nós [Brasil] não reflete. Tanto é que não reflete que existe uma disparidade muito grande de recebimento de valores econômicos por parte da população".

P2: "Não. Eu não acredito nisso. Eu acho que depende de muitos outros fatores além de só investir em desenvolvimento tecnológico. Porque ainda é um negócio muito monopolizado. Conhecimento [educação] não são todos que têm acesso. E quem vai usufruir desses ganhos econômicos? Se eles ocorressem de maneira geral e compartilhada entre todos os setores da sociedade, aí sim. Mas, aqui no Brasil não funciona. Vai ser para algumas elites, até dentro das universidades".
As (in)certezas: o desenvolvimento tecnológico em debate 
\begin{tabular}{|l|l|}
\hline P15: “Não, eu não corroboro essa frase. Acho que infelizmente não é & $\begin{array}{l}\text { As (in)certezas: o } \\
\text { assim, diretamente proporcional, e tem muitos vieses aí, políticos e de } \\
\text { corporativismo também, e das oligarquias dominantes nessa questão da } \\
\text { tecnológiconto em } \\
\text { tecnologia". }\end{array}$ \\
\begin{tabular}{l} 
debate \\
\hline
\end{tabular}
\end{tabular}

Fonte: Dos autores (2018)

A partir deste ponto as duas subcategorias serão discutidas por meio de um texto síntese - descrição - no qual estabelecemos, também, relações - análise/interpretação - com os elementos construídos ao longo do trabalho.

\subsection{A prevalência do modelo linear de desenvolvimento: a tecnologia neutra e determinista no contexto capitalista}

Ao examinar as primeiras unidades de análise é possível perceber que elas refletem a prevalência de concepções sobre um desenvolvimento tecnológico neutro e determinista.

Eu concordo, porque a gente sabe, por exemplo, que a construção civil movimenta mais de $50 \%$ da economia do país. Então se o mercado está aquecido, as pessoas vão ter mais emprego. A gente sabe que a construção civil abrange muito a questão da empregabilidade do nosso país. Se as pessoas têm um emprego, elas vão comprar mais, isso fomenta a economia. Se fomenta a economia, as pessoas vão ter mais qualidade de vida, porque elas vão ter condições de adquirir coisas melhores. Vão ter condições de fazer também viagens, isso é lazer, então vai melhorar a qualidade de vida delas. Eu concordo plenamente com essa afirmativa de que se tu investir em tecnologia, tu vai ter um conjunto de melhorias no país sim (P29).

Uma fala dessa natureza, presente direta ou indiretamente nas demais unidades de análise da presente subcategoria, revela que esse conjunto expressivo de professores se aproxima do primeiro segmento da comunidade de pesquisa destacado por Dagnino (2014; 2016). Por compreenderem que as soluções tecnológicas propostas pela Engenharia são, via de regra, promotoras de benefícios para o conjunto da população, tais entrevistados amenizam os efeitos colaterais da falta de controle externo e de valores éticos.

Mesmo as incipientes vinculações com desenvolvimento social revelam grandes fragilidades acerca do entendimento do que sejam benefícios e ganhos coletivos e/ou principalmente para os atores que operam na contra-hegemonia do desenvolvimento tecnológico.

Na verdade, quando se busca o desenvolvimento de tecnologias, indiretamente ou até diretamente, vai afetar a população. É um ganho social quando se tem um desenvolvimento tecnológico $(P 1)$.

Esse aspecto, para o contexto da UFFS, toma uma importância de considerável magnitude. Fazer movimentos e proposições para uma educação em Engenharia numa perspectiva sociotécnica tendo presentes concepções dessa natureza é um trabalho árduo. Como articular o desenvolvimento de Tecnologias Sociais se o contexto capitalista está arraigado - e disfarçado (in)conscientemente - em termos como mercado e emprego?

Confiar ingenuamente nesse ente mercado que, aproveitando os investimentos em desenvolvimento tecnológico, será promotor de melhores empregos e salários e, 
consequentemente, de melhor qualidade de vida para a população - inteira - é um entendimento que exime o profissional de Engenharia da responsabilidade pelo desenvolvimento social.

Isso é, no mínimo, preocupante. Para ser mais objetivo, diríamos que é pouco admissível no contexto de uma universidade pública e popular preocupada com o desenvolvimento regional integrado, sustentável e solidário e com forte vinculação com movimentos sociais. Neste ponto, já é possível vislumbrar a necessidade de novas compreensões epistemológicas acerca da tecnologia o que denota, de antemão, a necessidade de formação docente nesse campo.

\subsection{As (in)certezas: o desenvolvimento tecnológico em debate}

Há, entre o conjunto de unidades de análise, compreensões que questionam - colocam em debate - o desenvolvimento tecnológico atual. Entretanto a grande parte dessas unidades carregam a confiança no modelo linear de desenvolvimento desde que haja alguma condição. Isso é representado por expressões do tipo "está certo, mas", "sim, se", "sim, o que não significa".

Compreensões dessa natureza revelam um conjunto de professores que se aproxima do segundo segmento da comunidade de pesquisa destacado por Dagnino (2014; 2016). Mais críticos que os integrantes do primeiro grupo, ainda disseminam o determinismo da tecnologia visto que a aposta é que na existência de um sistema - mundo - ideal os benefícios do desenvolvimento tecnológico estariam a serviço da coletividade. Mais sensíveis e menos resistentes que os integrantes do primeiro grupo, a aposta que fazemos é que o trabalho de formação e sensibilização para uma educação em Engenharia numa perspectiva sociotécnica deva ser iniciado por este grupo.

O que dizer das últimas unidades de análise do quadro 1 ? Se as anteriores colocam em debate o desenvolvimento de soluções tecnológicas, estas o colocam em xeque frente a uma realidade mais crítica e menos ingênua.

As duas coisas não convergem para o mesmo ponto quando se fala em desenvolvimento, desenvolvimento tecnológico e desenvolvimento social. Até porque o desenvolvimento tecnológico, eu acho que está muito mais pautado em desenvolvimento puramente econômico, associado a um modelo capitalista. Eu não acho que tem que parar de se desenvolver economicamente, desenvolver tecnologia, mas eu acho sim que deveriam repensar os modelos de desenvolvimento dessas tecnologias. Quem é que está arcando com os ônus? Quem é que está com os bônus disso? (P2).

A gente tem que mostrar que a tecnologia é importante, mas também é necessário a participação de algumas diferentes entidades e a população precisa se envolver nesse contexto, todas as realidades precisam ter acesso à tecnologia. Eu acho que o governo investe pouco em tornar a tecnologia difusa na sociedade, ele acaba investindo em poucas áreas da tecnologia e essa frase [do modelo linear de desenvolvimento] ela não tem sentido. Essa frase ela teria sentido, em um aspecto muito ideal em países mais desenvolvidos que tem pouco problema de miséria, fome e pouco problema relacionado à dificuldade com acesso. E funciona porque daí tu atinge de maneira mais fácil a população, a tecnologia não 
tem atingido de maneira tão fácil. Mas eu não tenho muito subsídio para falar sobre esse tema, porque eu não estudo isso, mas do que isso eu não consigo te falar (P9).

Em menor número, é certo, as concepções desse conjunto de professores estão, em grande medida, alinhadas com a perspectiva sociotécnica de educação defendida nesse trabalho. Mesmo que alguns entrevistados destaquem a falta de subsídios para alicerçar suas ideias, os mesmos constituem importantes presenças nos cursos de Engenharia objetos dessa análise.

\section{Considerações finais}

Ao encaminhar o trabalho para as considerações finais convém destacar que a prevalência de concepções tradicionais acerca do desenvolvimento tecnológico reforça a falta de entendimento e comprometimento acerca do papel social da Engenharia e revela a dificuldade de superação de modelos formativos historicamente consolidados.

Convém destacar, portanto, que a sólida formação técnica e tecnológica que os cursos de engenharia se esforçam para promover está, neste trabalho, sendo questionada, uma vez que compreendemos que tal solidez só será plena na medida em que as questões do desenvolvimento social estejam, de fato, presentes no cenário educativo. Caso contrário, o compromisso da engenharia com o desenvolvimento de tecnologias, em atendimento às demandas da sociedade, continuará revestido de um caráter seletivo e parcelar. Num olhar crítico sobre esse cenário é possível entender porque uma formação na qual os aspectos políticos, sociais, econômicos, ambientais e culturais sejam parte integrante das soluções tecnológicas se mantém, historicamente, no status de utopia.

Ao passo que entendemos e destacamos o potencial da Engenharia como propulsora de desenvolvimento, reiteramos a necessidade de uma formação mais consistente, integradora e interdisciplinar, na qual as soluções tecnológicas sejam direcionadas por uma abordagem sociotécnica. As dificuldades de entender o caráter interativo e integrativo das soluções tecnológicas frente aos aspectos sociais denotam a necessidade de implantação de políticas e programas de formação de professores para a adequação sociotécnica.

Ao fazer frente a uma Engenharia para além do capital, as construções feitas ao longo desse trabalho nos apontam o desenvolvimento de Tecnologias Sociais como elemento estruturador de uma nova dinâmica de formação e atuação dos profissionais de Engenharia. Operar na perspectiva - educacional e profissional - de que as soluções de engenharia são sempre de caráter sociotécnico é atuar para além das forças do mercado capitalista e contribuir, em diferentes contextos, para a promoção de soluções mais inclusivas, participativas e democráticas.

\section{Referências}

AULER, Décio. Enfoque Ciência-Tecnologia-Sociedade: pressupostos para o contexto brasileiro.

Revista Ciência \& Ensino, v. 1, número especial, p. 1-20, nov. 2007.

BARDIN, Laurence. Análise de Conteúdo. Lisboa: Edições 70, 1977. 
BAZZO, Walter Antonio. Ciência, tecnologia e sociedade: e o contexto da educação tecnológica, 1998, 267p, Tese (Doutorado em Educação) - Universidade Federal de Santa Catarina, Florianópolis, 1998.

BAZZO, Walter Antonio. Ciência, Tecnologia e Sociedade e o contexto da educação tecnológica. 4. ed. rev. Florianópolis: Ed. da UFSC, 2014.

BRASIL. Resolução CNE/CES 11/2002. Diário Oficial da União, Brasília, 9 de abril de 2002. Seção 1, p. 32-35.

BRASIL. Resolução CNE/CES 2/2019: Diretrizes Curriculares Nacionais do Curso de Graduação em Engenharia. Brasília, 2019.

CARLETTO, Marcia Regina. Avaliação de impacto tecnológico: alternativas e desafios para a educação crítica em engenharia, 2009, 283p, Tese (Doutorado em Educação Científica e Tecnológica) - Universidade Federal de Santa Catarina, Florianópolis, 2008.

DAGNINO, Renato Peixoto. A anomalia da política de ciência e tecnologia. Revista Brasileira de Estudos Sociais, São Paulo, v. 29, n. 86, p. 45-58, out. 2014.

DAGNINO, Renato Peixoto. A Anomalia da Política de C\&T e sua Atipicidade Periférica. Revista Iberoamericana de Ciencia, Tecnología y Sociedad, v. 11, n. 33, p. 33-63, set. 2016.

ENGERS, M. E. A. A pesquisa no contexto da universidade: um novo olhar para a realidade da PUCRS. Educação Brasileira, Brasília, v. 22, n. 44, p. 131-154, jan./jun. 2000.

FRAGA, Laís Silveira. O curso de Graduação da Faculdade de Engenharia de Alimentos da UNICAMP: uma análise a partir da Educação em Ciência, Tecnologia e Sociedade, 2007, 86p, Dissertação (Mestrado em Política Científica e Tecnológica) - Universidade Estadual de Campinas, Campinas, 2007.

JACINSKI. Edson. Sentidos das interações entre tecnologia e sociedade na formação de engenheiros: limites e possibilidades para repensar a educação tecnológica. 2012, 363p, Tese (Doutorado em Educação Científica e Tecnológica) - Universidade Federal de Santa Catarina, Florianópolis, 2012.

LINSINGEN, Irlan. Engenharia, tecnologia e sociedade: novas perspectivas para uma formação, 2002, 210p, Tese (Doutorado em Educação) - Universidade Federal de Santa Catarina, Florianópolis, 2002.

MENESTRINA, Tatiana Comiotto. Concepção de Ciência, Tecnologia e Sociedade na formação de engenheiros: um estudo de caso das engenharias da UDESC Joinville. 2008, 237p, Tese (Doutorado em Educação Cientifica e Tecnológica) - Universidade Federal de Santa Catarina, Florianópolis, 2008.

MORAES, Roque. Análise de conteúdo. Revista Educação, Porto Alegre, v. 22, n. 37, p. 7-32, 1999.

PACEY. Arnold. La Cultura de la Tecnología. Cidade do México: Fondo de Cultura Económica, 1990. 
UFFS. PDI: Plano de Desenvolvimento Institucional 2019-2023. Chapecó: UFFS, 2019. Disponível em: https://www.uffs.edu.br/institucional/a_uffs/a_instituicao/plano_de_desenvolvimento_i nstitucional/pdi-2019-2023/@@download/file>. Acesso em: 05 set. 2021. 